\title{
FAKTOR YANG MEMPENGARUHI TINGKAT KUNJUNGAN TAMAN TEMATIK: STUDI KASUS TAMAN SKATEBOARD PALEMBANG
}

\author{
Fran Sinatra ${ }^{1}$, Helmia Adita Fitra ${ }^{1}$ \\ ${ }^{1}$ Perencanaan Wilayah dan Kota, Jurusan Teknologi Infrastruktur dan Kewilayahan, Institut Teknologi Sumatera \\ ${ }^{1}$ Email : fran.sinatra@pwk.itera.ac.id \\ DOI: 10.35472/jppk.v1i1.602
}

\begin{abstract}
The realization of sustainable development goals is a major concern today. Related to the development of urban areas, this goal is contained in the 11th goal, which is to create sustainable cities and communities. One of the efforts to achieve this goal is through the provision of good public open spaces. Public open space has a role as a space for interaction and social space for its people. The development of thematic parks is one of the efforts to maximize the social benefits of public open spaces so that sustainable urban and community development can be realized. This study aims to identify the factors that influence visits to thematic parks. The method used is descriptive quantitative method using regression analysis. The incidental sampling technique used in this study, where the respondents were park visitors. The results show that the factors that greatly affect the frequency of thematic park visits are influenced by gender and interactions in the community, while other factors such as age, distance, and dominant factors.
\end{abstract}

Keywords: Sustainable Development, Public Open Space, Thematic Park

\section{A. PENDAHULUAN}

Tingginya tingkat urbanisasi menyebabkan jumlah penduduk yang menetap di kawasan perkotaan meningkat setiap tahunnya. Diperkirakan pada tahun 2015 jumlah penduduk yang tinggal di kawasan perkotaan di Indonesia melebihi 50\%. Tingginya jumlah penduduk tentunya berdampak pada penyedian infrastruktur perkotaan seperti kawasan permukiman, perdagangan dan jasa, dan berbagai prasarana dan utilitas perkotaan. Hal ini tentunya berdampak pada peningkatan alih fungsi lahan menjadi kawasan terbangun.

Persoalan timbul seringkali disebabkan kota-kota yang ada di Indonesia terlambat dalam mengantisipasi laju urbanisasi ini sehingga menimbukan berbagai persoalan lingkungan. Kemacetan, polusi udara, kurangnya ruang publik untuk interaksi sosial secara langsung maupun tidak akan mempengaruhi kesehatan dan kesejahteraan masyarakatnya.

Indonesia sebagai salah satu Negara yang meratifikasi Tujuan Pembangunan Berkelanjutan (SDGs) hendaknya dapat menyusun arahan pembangunan mengarah pada perbaikan terutama pada tujuan ke-11 menciptakan kota dan komunitas yang berkelanjutan. Salah satu upaya untuk mendukung tujuan ke 11 SDGs hal yang dapat dilakukan melalui peningkatan kualitas dan kuantitas ruang terbuka publik (RTP) di kawasan perkotaan. Tidak hanya menciptakan keidahan RTP ini memerankan peranan 
yang penting dalam peningkatan kesejahteraan publik melalui penyediaan ruang sosial untuk berinteraksi.

Di Kota Palembang, Jumlah ruang terbuka publik khususnya RTH publik masih di bawah 20\% dari luas kota sesuai dengan amanat Undang-Undang No 26 tahun 2007 tentang penataan ruang. RTH perkotaan adalah bagian dari ruang-ruang terbuka (open space) suatu wilayah perkotaan yang diisi oleh tumbuhan, tanaman, dan vegetasi (endemik maupun introduksi) guna mendukung manfaat ekologis, sosial-budaya dan arsitektural yang dapat memberikan manfaat ekonomi (kesejahteraan) bagi masyarakatnya. RTH merupakan bagian dari ruang terbuka publik yang secara umum merupakan ruang terbuka yang pemanfaatannya lebih bersifat pengisian ruang hijau tanaman atau tumbuhan secara alamiah ataupun tanaman budidaya oleh manusia (Dirjen Penataan Ruang Departemen PU, 2006). Ada beberapa tipologi dari RTH Publik, seperti taman kota, jalur hijau bantanran sungai. Taman Kota merupakan bentuk dari RTH yang terbuka untuk umum dan dapat diakses oleh berbagai kalangan (Permendagri, 1 Tahun 2007 tentang Penataan Ruang Terbuka Hijau Kawasan Perkotaan).

Strategi yang dapat dilakukan dalam penciptaan ruang interaksi sosial dapat dilakukan melalui penyediaan taman tematik. Taman tematik dengan inovasi desain dan atraksi yang disajikan dapat menarik minat masyarakt untuk mengunjungi taman tersebut (Muqarabin, 2016). Taman tematik ini ditujukan untuk memfasilitasi kegiatan tertentu dalam lingkungan taman. Pemerintah Kota Palembang telah melakukan revitalisasi taman kota yang salah satunya adalah taman SkateBoard. Taman ini diharapkan dapat meningkatkan ruang interaksi sosial baik masyarakat umum maupun komunitas tertentu terutama komunitas skateboard.

Tingginya manfaat dari taman tematik sebagai ruang publik dalam upaya meningkatkan fungsi sosial sangat dipengaruhi oleh frekuensi kunjungan. Semakin tinggi kunjungan terhadap taman menjadi salah satu indikator tingginya manfaat dari taman kota tersebut (Zhang dan Zhou, 2018). Ada beberapa faktor yang perlu dikaji terkait motivasi untuk melihat tingginya minat mengunjungi taman tematik. Penelitian terdahulu dapat diungkapkan beberapa faktor yang berpengaruh terhadap tingkat kunjungan taman diantaranya: faktor jarak taman dari asal pengunjung (Zhang dan Zhou, 2018); faktor umur dan gender; umur remaja dominan dan laki laki dan kesesuaian aktifitas aktif seperti olahraga (Saleem dan Kamboh, 2013); faktor aktrasi yang disediakan dalam taman berupa kesesuaian aktifitas dengan karateristik atau tema taman dan keterlibatan suatu kelompok masyarakat dalam komunitas tertentu yang membutuhkan ruang terbuka (Sinatra dan Pontoh, 2017).

Motivasi kunjungan ke taman kota khusunya taman tematik tentunya akan berbedabeda yang sangat dipengaruhi oleh karakteristik masyarakat dan kondisi sosial. Oleh karenanya, Palembang sebagai Kota Metropolitan di Pulau Sumatera, diperlukan kajian yang komperehensi terkait faktor yang mempengaruhi kunjungan taman kota terutama tean tematik sehingga kedepannya dapat menjadi pertimbangan bagi pemerintah daerah dalam menyususn strategi untuk penyediaan dan revitalisasi taman kota dengan tujuan memaksimalkan manfaat secara sosial. 


\section{B. METODE PENELITIAN}

Berdasarkan tujuan, penelitian ini digolongkan kedalam penelitian deskriptif dengan pendekatan analisis menggunakan analisis deskriptif kuantitatif. Penelitian deskriptif kuantitatif merupakan penelitian yang mencoba memberi gambaran secara utuh dan ilmiah terhadap objek yang diteliti (Sugiono, 2018). Tenik pengumpulan data dilakukan melalui penyebaran kuisioner dan observasi lapangan. Teknik sampling yang digunakan adalah accidental sampling. Jumlah responden yang digunakan menyesuaikan dari kejenuhan data. Data yang diperoleh kemudian dianalisis dengan menggunakan regresi liner sehingga diperoleh faktor yang berpengaruh terhadap kunjungan taman tematik. Ada lima faktor yang ditanyakan kepada responden terkait motifasi kunjungan taman skateboard, faktor tersebut diantaranya: Gender, umur, keterlibatan dalam komunitas, jarak rumah dengan taman, dan kesesuaian kegiatan yang dilakukan di taman dengan tema taman.

\section{HASIL DAN PEMBAHASAN}

Penelitian dilakukan di Taman Skatepark Palembang, taman ini direvitalisasi sebelum diselenggarakannya even Asian Games Tahun 2018. Taman skateboard berada di lokasi yang strategis tepatnya di Pusat Kota Palembang yang bersebelahan dengan Jembatan Ampera (lihat Gambar 1). Luas taman ini berkisar antara $8.000 \mathrm{~m}^{2}$, tidak hanya dilengkapi dengan fasilitas olah raga Skateboard taman ini juga didukung dengan fasilitas taman lainnya seperti bangku taman, jalur pedestrian, dan children play ground. Gambar di bawah ini menunjukan kondisi dan fasilitas yang ada di taman ini.

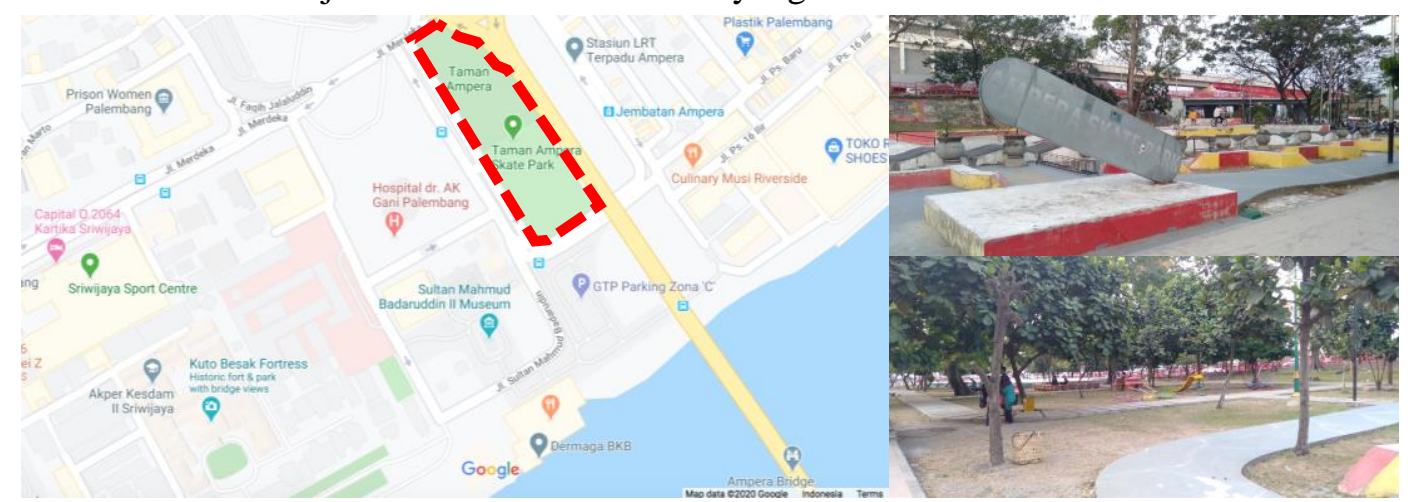

Sumber: Penulis, 2021

Gambar 1. Lokasi Taman Tematik Skatepark, Kota Palembang

Taman kota berperan besar dalam peningkatan kualitas kehidupan masyarakat perkotaan hal ini dikarenakan taman dapat memberikan pelayanan sosial kepada penduduk khususnya pengunjungang Taman Kota. Selain itu taman juga dapat berfungsi sebagai area untuk rekreasi, bersantai, dan berinteraksi ( Loures, 2007). Keberhasilan penyediaan taman dalam memaksimalkan manfaat yang dirasakan oleh masyarakat dapat dilihat dari tingkat kunjungan masyarakat ke taman kota tersbut. Variabel yang diuji dalam penelitian ini terkait dengan frekuensi kunjungan ke taman tematik Skateboard Palembang meliputi: gender (jenis kelamin), umur, keterlibatan dalam komunitas, jarak rumah dengan taman dan kesesuaian kegiatan. Pemodelan dilakukan dengan variabel 
frekuensi kunjungan sebagai variabel bebas dan variabel gender, umur, keterlibatan dalam komunitas, jarak rumah dengan taman dan kesesuaian kegiatan sebagai variabel terikat.

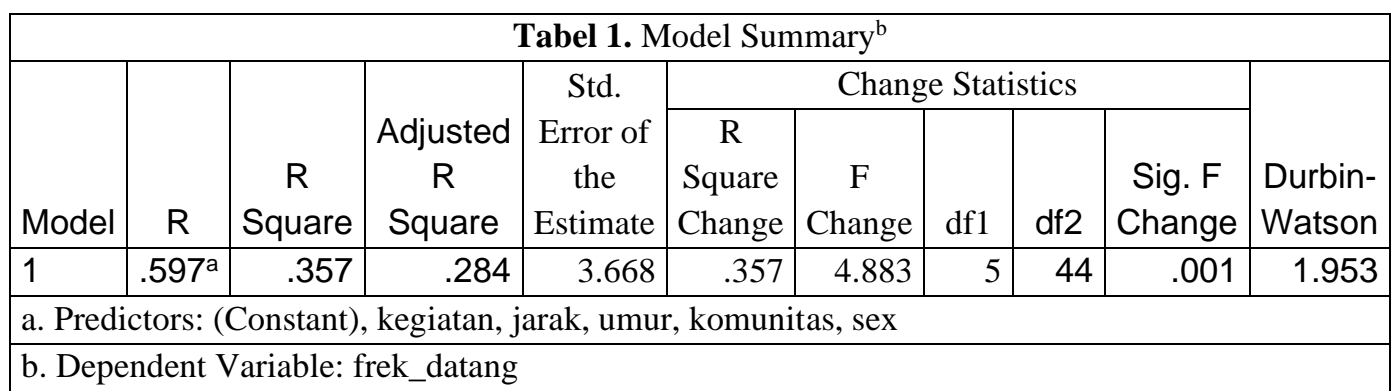

Sumber: Penulis, 2021

Model regresi ini kurang mampu merepresentasikan model yang ada hal ini dikarekan model ini hanya mampu menjelaskan $59 \%$ kondisi ril, artinya ada variable lain yang mempengaruhi variable frekuensi kedatangan sebesar $41 \%$ variable lain yang dapat mempengaruhi kedatangan.

\begin{tabular}{|c|c|c|c|c|c|c|}
\hline \multicolumn{7}{|c|}{ Table 2 Anova } \\
\hline \multicolumn{2}{|c|}{ Model } & Sum of Squares & $\mathrm{df}$ & Mean Square & $\mathrm{F}$ & Sig. \\
\hline \multirow[t]{3}{*}{1} & Regression & 328.509 & 5 & 65.702 & 4.883 & $.001^{\mathrm{b}}$ \\
\hline & Residual & 591.971 & 44 & 13.454 & & \\
\hline & Total & 920.480 & 49 & & & \\
\hline \multicolumn{7}{|c|}{ a. Dependent Variable: frek_datang } \\
\hline
\end{tabular}
Sumber: Penulis, 2021

Meskipun model ini tidak terlalu kuat menjelaskan hubungan variable bebas dengan variable terikat, model ini tetap dipakai dalam analisis karena nilai signifikansinya kurang dari 0,5 .

Model ini bisa digunakan (nilai $\mathrm{R}>0,5$ ) tetapi model ini hanya bisa menjelaskan sebanyak $28,4 \%$ dari kenyataan. Artinya $71,6 \%$ faktor lainnya menentukan frekuensi kedatangan seseorang. Model ini memenuhi prinsip linearitas (nilai sig. model pada tabel Annnova adalah $<0,05$ ). Tabel 1 . berikut menunjukan resume dari pemodelan dengan menggunakan software SPSS terkait pemodelan yang dilakukan.

\begin{tabular}{|c|c|c|c|c|c|c|c|c|c|c|}
\hline \multicolumn{11}{|c|}{ Tabel 3. Hasil Pemodelan } \\
\hline \multirow[b]{2}{*}{ Model } & \multirow[b]{2}{*}{$\mathrm{R}$} & \multirow[b]{2}{*}{$\begin{array}{c}\mathrm{R} \\
\text { Square }\end{array}$} & \multirow[b]{2}{*}{$\begin{array}{l}\text { Adjusted } \\
\text { R Square }\end{array}$} & \multirow[b]{2}{*}{$\begin{array}{l}\text { Std. Error } \\
\text { of the } \\
\text { Estimate }\end{array}$} & \multicolumn{5}{|c|}{ Change Statistics } & \multirow[b]{2}{*}{$\begin{array}{l}\text { Durbin- } \\
\text { Watson }\end{array}$} \\
\hline & & & & & $\begin{array}{c}\mathrm{R} \\
\text { Square } \\
\text { Change }\end{array}$ & $\begin{array}{c}\mathrm{F} \\
\text { Change }\end{array}$ & df1 & df2 & $\begin{array}{c}\text { Sig. F } \\
\text { Change }\end{array}$ & \\
\hline 1 & $.597^{\mathrm{a}}$ & .357 & .284 & 3.668 & .357 & 4.883 & 5 & 44 & .001 & 1.953 \\
\hline
\end{tabular}

Sumber: Penulis, 2021 


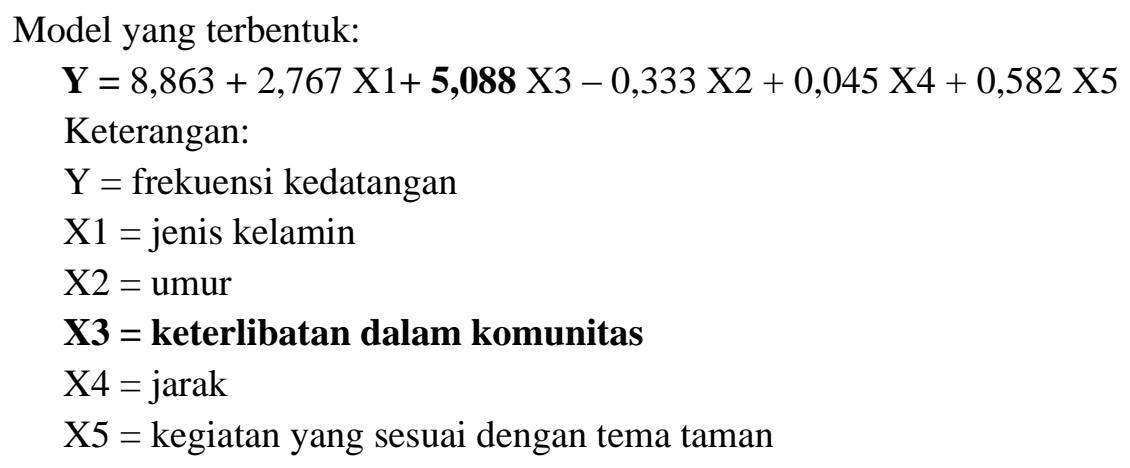

Dari model, didapat kesimpulan bahwa faktor yang signifikan mempengaruhi frekuensi kedatangan seseorang hanya keterlibatan dalam komunitas. Adapun faktor lain tidak dapat dimasukkan karena nilai signifikansi besar dari 0,05 (faktor Gender/ jenis kelamin, umur, jarak dan kegiatan dianggap tidak signifikan untuk memprediksi frekuensi kedatangan seseorang ke taman) Penjelasan dari model: kecenderungan jenis kelamin yang sering datang adalah laki-laki (nilai koef positif) dan semakin orang terlibat banyak dalam komunitas, maka kecenderungannya akan sering datang/ mengunjungi taman.

\section{SIMPULAN DAN SARAN}

Manfaat ruang terbuka publik khususnya taman tematik sangat dipengaruhi oleh tingkat kunjungan. Variable yang diuji dalam mengetahui faktor yang berpengaruh terhadap tingkat atau frekuensi kunjungan taman tematik Skatepark di Kota Palembang meliputi: Jenis kelamin (gender); Umur; Keterlibatan dalam komunitas; Jarak rumah dengan Taman; kesesuaian kegiatan dengan tema taman. Hasil pemodelan yang dilakukan menunjukan bahwa faktor atau variabel yang berpengaruh terhadap frekuensi kunjungan ke Taman Tematik Skatepark Palembang adalah keterlibatan komunitas sedangkan faktor lain tidak berpengaruh secara signifikan. Kedepannya penelitian ini perlu dilakukan pendalaman dengan tidak hanya menguji satu taman tematik untuk mendapatkan gambaran secara utuh sebagai perbandingan.

\section{DAFTAR PUSTAKA}

[1] Ayesha Saleem dan Khalique Kamboh. 2013. WHY PEOPLE VISIT PARKS? THE ROLE OF GENDER, AGE AND EDUCATION AMONG URBAN PARK VISITORS IN FAISALABAD. International Journal of Asian Social Science. http://www.aessweb.com/pdf-files/ijass\%203(10),\%202196-2203.pdf.

[2] Carmona. 2018. Place value: place quality and its impact on health, social, economic and environmental outcome. Journal of Urban Design.

[3] Evans, Kirby, Knight, Shackell, Westley. Public Health and Landscape Creating healthy place [serial on line]. 2013. Available from URL: https://www.landscapeinstitute.org/wpcontent/uploads/2013/11/PublicHealthandLandscape_FINAL_singlepage.pdf. Diakses September 2018.

[4] Joga dan Ismaun. RTH 30\%: Resolusi Kota Hijau. 2011. Jakarta.

[5] Kementerian Kesehatan Republik Indonesia. GERMAS wujudkan Indonesia Sehat [serial on line] 2016. Available from URL: http://www.depkes.go.id/article/view/16111500002/germas-wujudkan-indonesiasehat.html. Diakses September 2018 
[6] Luis Loures, Raul Santos, dan Thomas Panagopoulos. 2007. Urban Parks and Sustainable City Planning-The case of Portimao, Portugal. https://www.researchgate.net/publication/228860531_Urban_Parks_and_Sustainable _City_Planning-The_Case_of_Portimao_Portugal

[7] Muqarabin, M. 2016. Evaluasi Taman-Taman Tematik Kota Bandung Berdasarkan Persepsi dan Preferensi Masyarakat Sekitar. Tesis. Magiter Rancang Kota ITB

[8] Sai Zhang, dan Weiqi Zhou. 2018. Recreational visits to urban parks and factors affecting park visits: Evidence from geotagged social media data. Journal Landscape and Urban Planning. https://www.sciencedirect.com/science/article/pii/S0169204618307370

[9] Sinatra, F., Kurniasih, dan Indradjati. 2017. Identifying Creative Urban Landscape Towards Creative Tourism in Bandung: A Preliminary Study.

[10] UNDP. Sustainable Development Goals [serial on line]. Available from URL: http://www.undp.org/content/undp/en/home/sustainable-development-goals.html.

Diakses September 2018.Carmona. 2018. Place value: place quality and its impact on health, social, economic and environmental outcome. Journal of Urban Design. https://www.tandfonline.com/doi/full/10.1080/13574809.2018.1472523

[11] UNESCO. Inclusion Through Access to Public Space [serial on line] 2017. Available from URL:http://www.unesco.org/new/en/social-and-humansciences/themes/urban- development/migrants-inclusion-in-cities/goodpractices/inclusion-through-access-to-public- space/. Diakses September 2018

[12] World Health Organization (WHO). Urban population growth:Global Health Observatory Data [serial on line] 2018. Available from URL: http://www.who.int/gho/urban_health/situation_trends/urban_population_growth_text/ en/. Diakses September 2018 